\title{
Influence of Parameters on the Pre-Reduction Process of Vanadium-Titanium Magnetite Carbon-Containing Composite Pellets in Rotary Kiln
}

\author{
Bo Wang (D), Xueyong Ding *, Tianhua Ju, Xiaofei Zhang and Gongjin Cheng * \\ School of Metallurgy, Northeastern University, Shenyang 110819, China; 1510246@stu.neu.edu.cn (B.W.); \\ jthua89@hotmail.com (T.J.); wertyzxf@outlook.com (X.Z.) \\ * Correspondence: xyding@mail.neu.edu.cn (X.D.); chenggj@smm.neu.edu.cn (G.C.)
}

check for updates

Citation: Wang, B.; Ding, X.; Ju, T.; Zhang, X.; Cheng, G. Influence of Parameters on the Pre-Reduction Process of Vanadium-Titanium Magnetite Carbon-Containing Composite Pellets in Rotary Kiln. Metals 2021, 11, 45. https://doi.org/ 10.3390/met11010045

Received: 24 November 2020 Accepted: 24 December 2020 Published: 28 December 2020

Publisher's Note: MDPI stays neutral with regard to jurisdictional claims in published maps and institutional affiliations.

Copyright: () 2020 by the authors. Licensee MDPI, Basel, Switzerland. This article is an open access article distributed under the terms and conditions of the Creative Commons Attribution (CC BY) license (https: / / creativecommons.org/ licenses/by/4.0/).

\begin{abstract}
A novel smelting reduction process called pre-reduction in rotary kiln and total oxygen melting pool is a promising route to reduce environmental pollution from the ironmaking industry. In this paper, the process parameters and appropriate efficiency of reduction in the pre-reduction process of the rotary kiln were investigated via the detection of the metallization rate, phase composition, and internal morphology of the product combining with the analysis of the off-gas. The results indicated that the parameters of reduction temperature, reduction holding time, and coal ratio have a remarkable influence on the metallization rate. The reduction temperature has the most significant effect, followed by the reduction time and the coal ratio. Furthermore, under the condition of reduction temperature $1000{ }^{\circ} \mathrm{C}$, holding time $30 \mathrm{~min}$, coal ratio $=1$, a product with a metallization rate of more than $70 \%$ can be obtained, which meets the requirements of the rotary kiln process, and its $\mathrm{CO}_{2} / \mathrm{CO}$ value of the pre-reduction endpoint is appropriate. Continue to increase the temperature, holding time, and coal ratio can raise the metallization rate of the pellets, but only a little improvement and may cause reoxidation of the product.
\end{abstract}

Keywords: rotary kiln; vanadium titanium magnetite; lignite; ironmaking

\section{Introduction}

Ironmaking and steelmaking manufacturing is one of the most energy-intensive industries worldwide, using coal as the primary fuel making it the major contributor to the anthropogenic emissions of carbon dioxide in the world [1]. The annual world steel demand is expected to grow fast to 2200 million tonners in 2050 [2], which would drive a visible increase in the industry's absolute energy use and environmental pollution. Thus, alternative emerging or advanced energy efficiency with low-carbon technologies are necessary for iron and steel companies.

At present, the ironmaking process in the world is mainly based on the blast furnace (BF). Numerous institutions have focused on how to reduce energy consumption and the environmental pollution of blast furnaces. Many studies from around the world have identified that some commercially available energy-efficiency technologies such as pulverized coal injection (PCI) [3], iron coke hot briquette (ICHB) [4], and top gas recycle (TGR) [5] for $\mathrm{BF}$ has reduced the $\mathrm{CO}_{2}$ emission, but the serious resource shortage and crisis environmental problems still cannot be solved [6,7]. The main reason is that the blast furnace method must use high-grade ore and metallurgical coke, while the sintering and coking process will cause a lot of pollution. In order to make iron production gets rid of the dependence on metallurgical coke, the smelting reduction processes come into being.

The COREX method, as the first smelting reduction process for industrial production, has been successfully applied in India, South Korea, South Africa, and China [8]. Although COREX is considered as the most advanced iron-making process, it is still involved in some technical problems [9]. In particular, there is still a certain dependence on coke in actual 
production and has high requirements for coal [10]. In order to completely get rid of the dependence on coke, based on the analysis of the existing ironmaking processes (COREX, Romelt [11], etc.) and combining the characteristics of China's energy and resources, the Central Iron and Steel Research Institute creatively put forward a novel ironmaking process of pre-reduction in rotary kiln and total oxygen melting pool (PROM) [12,13], as shown in Figure 1. In this process, the coking and sintering step could be eliminated by replacing the coke and sinter with pulverized coal and fine ore, which simplify the process and environmentally friendly.

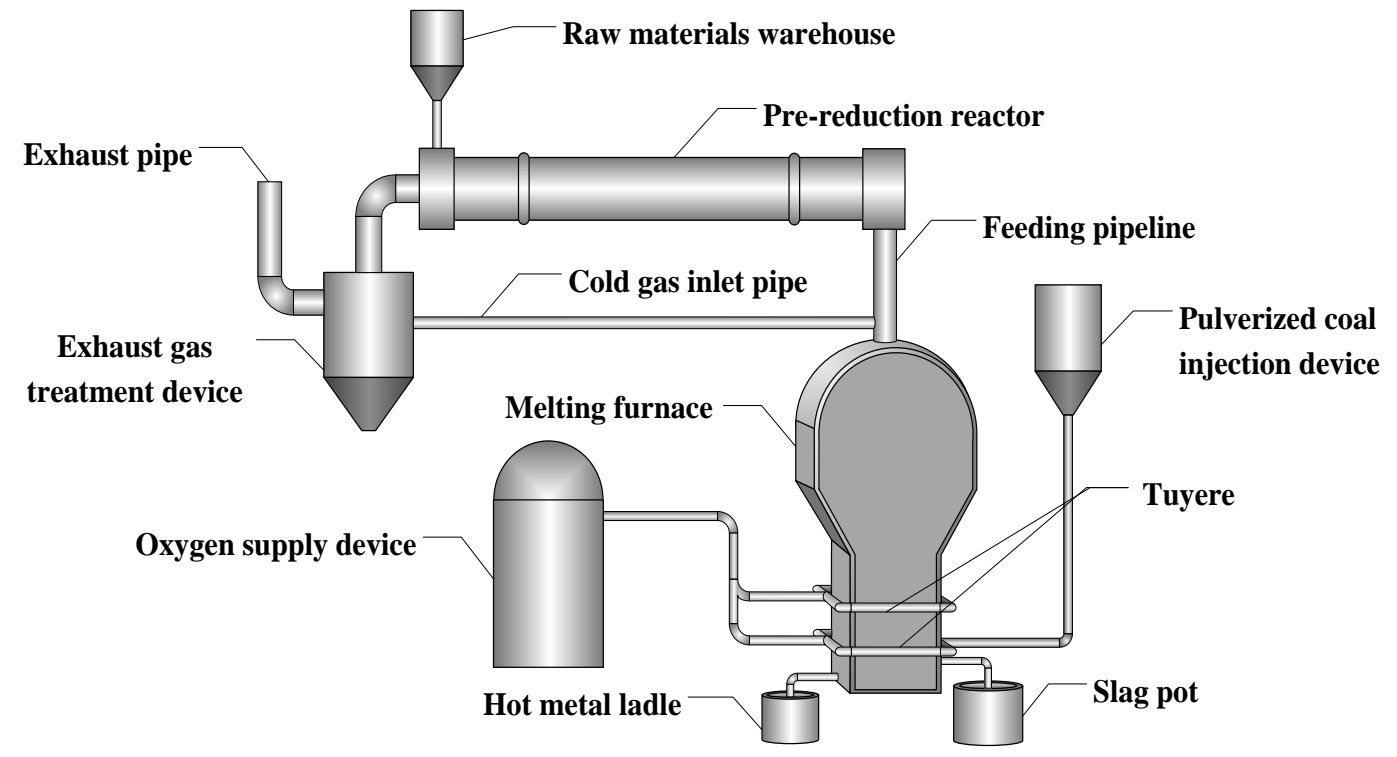

Figure 1. Flow chart of pre-reduction of rotary kiln and total oxygen melting pool process.

In Figure 1, the entire flow process could be mainly divided into two units, namely the pre-reduction by the rotary kiln and the final melting in the melting furnace. In the first unit, the raw materials are mixed, pelletized, and dried. Then, the pellets are fed into the rotary kiln from the end of the kiln, and exchange heat with the countercurrent hot flue gas burning in the rotary kiln. The pellets are heated to $900-1100{ }^{\circ} \mathrm{C}$, at the same time the iron oxide is reduced to metallic iron step by step. In the smelting phase, the obtained hot and pre-reduced pellets are then fed directly from the kiln head into the oxy-coal combustion smelting reduction furnace. Feeding the hot pre-reduced pellets into the smelting reduction furnace could reduce the energy consumption obviously [14]. The smelting reduction furnace is provided with two rows of the tuyere. The oxygen and pulverized coal are sprayed from the lower tuyere, and oxygen is injected from the upper tuyere. In the second part, the pre-reduced pellets are finally reduced and melted in the smelting reduction furnace to achieve slag-iron separate. The temperature and calorific value of the top gas produced by the smelting reduction furnace are very high. To meet the temperature requirement in the rotary kiln, the kiln tail gas produced by the rotary kiln is cooled, purified, and removed of carbon dioxide, and then get into the top of the smelting reduction furnace, thereby reducing the temperature of the smelting reduction gas to $900-1200{ }^{\circ} \mathrm{C}$, finally directly into the rotary kiln for combustion [15]. When compared with the BF process, the PROM process can directly produce liquid iron without using coking coal and sinter. Thus, the new process makes full use of the thermal and chemical energy of the top gas of the oxygen melting furnace and the exhaust gas of the pre-reduced rotary kiln. Therefore, as an alternative liquid iron production technology to the BF process, further research into the PROM process is of great significance.

As a typical type of complex iron ore with the coexistence of titanium and vanadium, vanadium-titanium magnetite (VTM) is widely distributed in China, the Americas, Russia, and South Africa, and has a high comprehensive utilization value. Statistics show that 
China possesses approximately 18 billion tons of VTM in the Panxi and Chengde Districts $[16,17]$. At present, VTM concentrates is mainly to make pig iron by smelting and separating in $\mathrm{BF}[18,19]$, but this method has many disadvantages that limit its development. Firstly, the BF process heavily relies on metallurgical coke and sintering. Secondly, due to the conditions of blast furnace smelting, the content of $\mathrm{TiO}_{2}$ in the titanium-bearing blast furnace slag is less than $25 \%$, which makes it very difficult to recover and utilize this element, resulting in the waste of resources [20-22]. Moreover, the operation of blast furnace smelting high-titanium vanadium-titanium magnetite is difficult [23]. Therefore, developing a more environmentally friendly alternative route to use the VTM concentrates efficiently becomes significant.

Through the establishment of mathematical model calculations and laboratory experiments [12,13], the Central Iron and Steel Research Institute has verified that using this process to smelt vanadium-titanium magnetite is technically feasible, and has great advantages in energy saving and environment protection compared with traditional BF process. At present, the technology has been listed as a national key research and development project, and an industrial demonstration production line is being erected in the west area of Panzhihua, Sichuan, China. The goal of the demonstration project of this new process is to reduce the energy consumption per ton of molten iron by $30 \%$, reduce production costs by $10 \%$ to $15 \%$, and reduce pollutant emissions by $50 \%$ to $80 \%$ compared with traditional blast furnaces.

For the typical two-step smelting reduction method, the quality of the pre-reduced product is critical to the subsequent process [9]. Due to the enclosed process and limitations of measuring instruments, it is difficult to study the pre-reduction conditions inside the rotary kiln directly on site. Therefore, laboratory research is very important for the selection of parameters in the pre-reduction unit of the new process.

In the past decades, the direct reduction of VTM concentrates by solid reductants has been widely researched [24-27]. It was found that the reduction of VTM concentrates was more difficult than magnetite due to the different crystal structures and the presence of titanium. In order to obtain a higher metallization rate (about 90\%), increasing the reaction temperature above $1250{ }^{\circ} \mathrm{C}$ or pre-oxidation was adopted [28,29]. However, the increasing temperature would cause the ring problem [30], and pre-oxidation needs additional equipment and increases energy consumption. Meanwhile, the traditional coalbased vanadium-titanium magnetite rotary kiln process requires a long time of roasting, which is not conducive to taking advantage of the rapid reduction of the total oxygen melting pool. Appropriately lowering the metallization rate can not only reduce the difficulty of reduction in the pre-reduction unit but also give full play to the technical advantages of smelting reduction. Therefore, the selection of reasonable pre-reduction process parameters and pre-reduction metallization rate is very important to the whole process. This process initially sets a pre-reduction metallization rate of $70 \%$.

In this paper, a series of experiments of coal containing VTM concentrates composites pellets reduction in a laboratory-scale under simulating rotary kiln were conducted. The effect of main operating parameters under rotary kiln conditions on the metallization rate was studied firstly. Subsequently, the pre-reduction behavior of the pellets under rotary kiln conditions was investigated. By analyzing the metallization rate, off-gas change behavior, phase transition and microstructure of the pellets, the appropriate process parameters for pre-reduction were proposed. Our study is expected to provide a theoretical basis and reference for the industrialization experiment of the new ironmaking process.

\section{Materials and Methods}

\subsection{Raw Materials}

The main raw materials used in this study included VTM concentrates, coal (lignite), and molasses. The VTM concentrate and coal were obtained from Pangang Group Co. Ltd. in Panzhihua, Sichuan, China. The chemical composition of VTM concentrate analyzed by the method of chemical analysis was listed in Table 1. The XRD pattern of VTM concentrate 
as shown in Figure 2 indicates that the main crystalline phases are magnetite $\left(\mathrm{Fe}_{3} \mathrm{O}_{4}\right)$, ilmenite $\left(\mathrm{FeTiO}_{3}\right.$ or $\left.\mathrm{FeO} \cdot \mathrm{TiO}_{2}\right)$, and titanomagnetite $\left(\mathrm{Fe}_{2.75} \mathrm{Ti}_{0.25} \mathrm{O}_{4}\right.$ or $\left.3\left(\mathrm{Fe}_{3} \mathrm{O}_{4}\right) \cdot \mathrm{Fe}_{2} \mathrm{TiO}_{4}\right)$. The reduction coals proximate analysis and the chemical compositions of ash analyzed by the chemical analysis were listed in Table 2, and its softening and melting properties (measured by the triangular cone method according to GB/T219-2008) were shown in Table 3.

Table 1. The chemical compositions of vanadium-titanium magnetite (VTM) concentrate (wt $\%$ ).

\begin{tabular}{cccccccc}
\hline $\mathbf{T F e}$ & $\mathrm{FeO}$ & $\mathrm{TiO}_{2}$ & $\mathrm{MgO}$ & $\mathrm{SiO}_{2}$ & $\mathrm{Al}_{2} \mathrm{O}_{3}$ & $\mathrm{CaO}$ & $\mathrm{V}_{\mathbf{2}} \mathrm{O}_{5}$ \\
\hline 55.55 & 29.31 & 10.27 & 2.28 & 4.88 & 4.11 & 1.47 & 0.62 \\
\hline
\end{tabular}

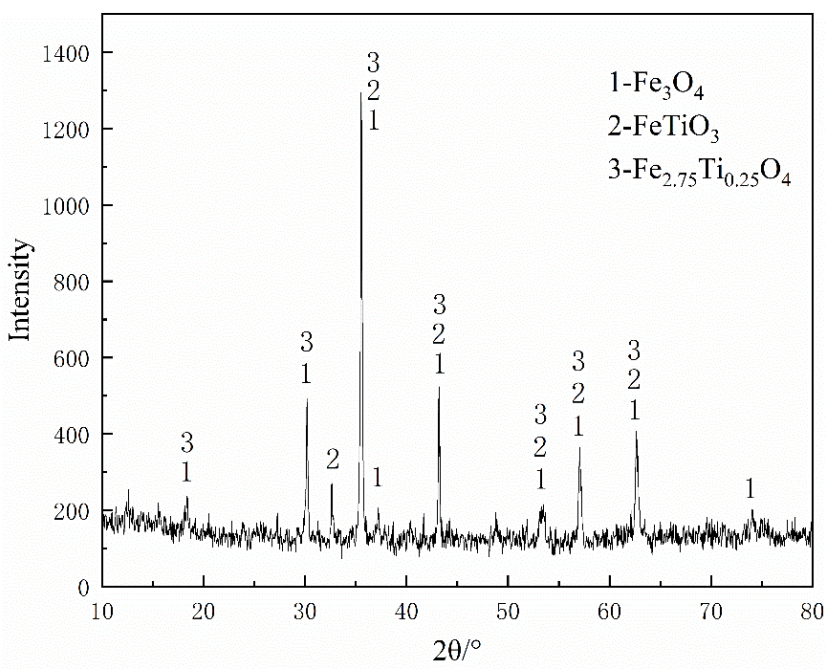

Figure 2. X-ray diffraction pattern of the VTM concentrate.

Table 2. Proximate analysis and ash chemical composition of the coal (wt $\%)$.

\begin{tabular}{cccccccccc}
\hline \multicolumn{4}{c}{ Proximate Analysis } & \multicolumn{7}{c}{ Ash Analysis } \\
\hline FC, ad & $\mathbf{V}$, ad & $\mathbf{A}$, ad & $\mathbf{M}$, ad & $\mathbf{S}$, ad & $\mathbf{C a O}$ & $\mathrm{SiO}_{2}$ & $\mathbf{M g O}$ & $\mathbf{A l}_{2} \mathbf{O}_{3}$ & $\mathbf{T F e}$ \\
\hline 58.85 & 31.03 & 4.46 & 5.66 & 0.49 & 20.64 & 44.44 & 0.66 & 20.03 & 6.32 \\
\hline
\end{tabular}

Notes: ad, on air-dry basis; FC, fixed carbon; V, volatile; A, ash; M, moisture; and S, total sulfur.

Table 3. Softening and melting properties of coal ash.

\begin{tabular}{ccccc}
\hline Item & DT & ST & HT & FT \\
\hline Value $^{\circ}{ }^{\circ} \mathrm{C}$ & 1080 & 1130 & 1180 & 1210 \\
\hline
\end{tabular}

Notes: DT, deformation temperature; ST, sphere temperature; HT, hemisphere temperature; and FT, flow temperature.

\subsection{Experimental Equipment and Methods}

VTM carbon composite pellets were prepared with a certain amount of VTM concentrates, coals, and molasses in a disc pelletizer (with a diameter of $600 \mathrm{~mm}$, an inclination of $45^{\circ}$, and a rotating speed of $18 \mathrm{r} \cdot \mathrm{min}^{-1}$ ). After pelletizing, these pellets were dried in an oven at $105^{\circ} \mathrm{C}$ for $5 \mathrm{~h}$, then pre-reduction experiments were carried out in a laboratory-scale simulator rotary kiln. The apparatus mainly consists of an electric resistance tube furnace (200 $\mathrm{mm}$ in diameter and $2300 \mathrm{~mm}$ in length), a gas control system, a temperature control system, and a gas analyzer, as shown in Figure 3. About $100 \mathrm{~g}$ of dried pellets with different coal ratio ( $\mathrm{C} / \mathrm{O}$ mole ratio) were put into the middle of the tube furnace, and then the tube furnace was heated to the specified temperature within $120 \mathrm{~min}$ and the reduction experiment was conducted. After the reduction experiment, the reduced samples were 
taken out and put into a graphite crucible soon with graphite powder quickly covered to prevent oxidation. After the sample cooled down to room temperature, take out the sample preparation for related testing. It must be emphasized that the furnace tube was kept rotating with a rotation speed of $2 \mathrm{r} \cdot \mathrm{min}^{-1}$ and under a $1 \mathrm{~L} \mathrm{~min}{ }^{-1}$ nitrogen atmosphere throughout the experiment.

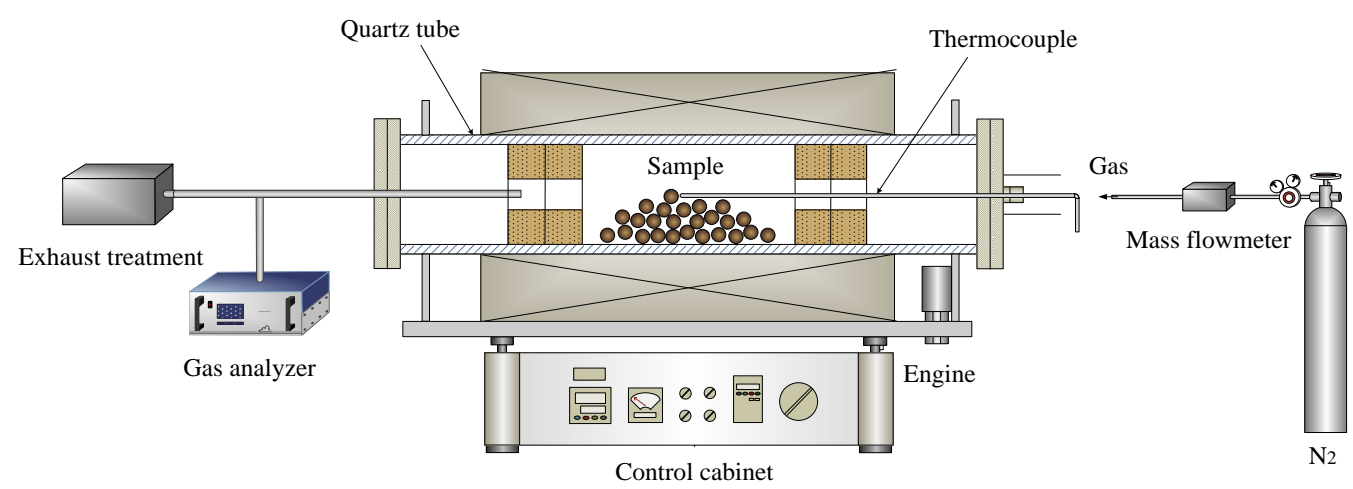

Figure 3. Schematic diagram of a laboratory-scale simulated rotary kiln.

To investigate the effect of reduction parameters on the metallization rate, an orthogonal array was applied in this metalizing test. Due to the holding temperature, holding time, and coal ratio are the most important technical parameters in the pre-reduction process, these three parameters were set to five levels in this study. After that, the single factor experiment was used to analyze the behaviors of each factor on the reduction process and the proposal parameters have been recommended.

The metallization rate of the pellet after the reaction was defined as the ratio of the content of metallic iron to the content of total iron in the pellet, which can be calculated as follows:

$$
M=[\omega(\mathrm{MFe}) / \omega(\mathrm{TFe})] \times 100 \%
$$

where $M$ is the metallization rate and $\omega(M F e)$ and $\omega(T F e)$ are the metallic iron content and total iron content in the reduced pellets, respectively.

The phase components of VTM and pre-reduced pellets were analyzed by X-ray diffraction (XRD, X'Pert Pro; PANalytical, Almelo, The Netherlands) with $\mathrm{Cu}$ K $\alpha$ radiation $(\lambda=1.5406 \AA)$, and the microstructure, element compositions, and distributions of the reduced pellet products prepared with polished section were examined by scanning electron microscope-energy dispersive spectroscopy (SEM-EDS, Ultra Plus; Carl Zeiss GmbH, Jena, Germany), for which the type of imaging used back-scattered electrons. The $\mathrm{CO}$ and $\mathrm{CO}_{2}$ contents in the off-gas were analyzed by a homemade gas analyzer.

\section{Results and Discussion}

\subsection{Orthogonal Tests Result for Lignite Containing VTM Composites}

The results of 25 orthogonal tests for metalizing are listed in Table 4 . It can be seen that the metallization rate distributes in the range of $11.14-85.59 \%$ and increased with the increase of reaction temperature. To clarify the effects of these parameters on the metallization rate, range analysis and variance analysis were adopted. The range analysis results are shown in Table 5. It should be pointed out that the value of Delta means the max-min of each five levels of each parameter, and the larger value of the Delta suggests the more important influence of the corresponding factor. The results show that the rank of effects on the metallization rate is: Temperature $>$ time $>$ coal ratio, namely the temperature is the remarkable factor, followed by the time. 
Table 4. Results of the orthogonal metallizing test.

\begin{tabular}{ccccc}
\hline Number & Temperature $\left({ }^{\circ} \mathbf{C}\right)$ & Time $(\mathbf{m i n})$ & Coal Ratio & Metallization Rate (\%) \\
\hline 1 & 900 & 10 & 0.6 & 11.14 \\
2 & 900 & 20 & 0.8 & 25.37 \\
3 & 900 & 30 & 1 & 34.21 \\
4 & 900 & 40 & 1.2 & 45.83 \\
5 & 900 & 50 & 1.4 & 48.55 \\
6 & 950 & 10 & 0.8 & 40.55 \\
7 & 950 & 20 & 1 & 49.67 \\
8 & 950 & 30 & 1.2 & 59.91 \\
9 & 950 & 40 & 1.4 & 65.37 \\
10 & 950 & 50 & 0.6 & 62.81 \\
11 & 1000 & 10 & 1 & 61.96 \\
12 & 1000 & 20 & 1.2 & 71.64 \\
13 & 1000 & 30 & 1.4 & 74.56 \\
14 & 1000 & 40 & 0.6 & 73.37 \\
15 & 1000 & 50 & 0.8 & 71.62 \\
16 & 1050 & 10 & 1.2 & 76.15 \\
17 & 1050 & 20 & 1.4 & 67.82 \\
18 & 1050 & 30 & 0.6 & 74.53 \\
19 & 1050 & 40 & 0.8 & 80.59 \\
20 & 1050 & 50 & 1 & 72.45 \\
21 & 1100 & 10 & 1.4 & 73.26 \\
22 & 1100 & 20 & 0.6 & 81.33 \\
23 & 1100 & 30 & 0.8 & 84.74 \\
24 & 1100 & 40 & 1 & 85.59 \\
25 & 1100 & 50 & 1.2 &
\end{tabular}

Table 5. Range analysis results of the orthogonal metallizing test.

\begin{tabular}{cccccccc}
\hline Parameter & $\mathbf{1}$ & $\mathbf{2}$ & $\mathbf{3}$ & $\mathbf{4}$ & $\mathbf{5}$ & Delta & Rank \\
\hline Temperature & 33.02 & 55.66 & 69.70 & 74.14 & 79.47 & 46.45 & 1 \\
Time & 51.54 & 59.22 & 63.57 & 67.49 & 70.18 & 18.64 & 2 \\
Coal ratio & 56.64 & 59.03 & 62.23 & 66.92 & 67.42 & 11.01 & 3 \\
\hline
\end{tabular}

Figure 4 shows the trend of average values of each parameter at five designated levels affecting the metallization rate. The metallization rate increases with the increase of all these three parameters. Notably, the temperature curve is steeper than two others, which means the effect of temperature on the metallization rate is most significant within the range of selected five levels for these three parameters. The variance analysis results for the metallization rates tests are listed in Table 6. The temperature $(F=112.99, p=0.000)$, time $(\mathrm{F}=17.53, p=0.000)$, and coal ratio $(\mathrm{F}=7.55, p=0.003)$ are dominant parameters and accounting for $81.25 \%, 12.6 \%$, and $5.43 \%$, respectively, of total contribution to the metallization rate.

Table 6. Variance analysis results for the metallization rates of pellets.

\begin{tabular}{ccccccc}
\hline Parameter & SS & DF & Var & $\boldsymbol{F}$ & $\boldsymbol{p}$ & Contribution (\%) \\
\hline Temperature & 6956.50 & 4 & 1739.13 & 112.99 & 0.000 & 81.25 \\
Time & 1079.03 & 4 & 269.76 & 17.53 & 0.000 & 12.6 \\
Coal ratio & 464.67 & 4 & 116.17 & 7.55 & 0.003 & 5.43 \\
Error & 184.70 & 12 & 15.39 & - & - & 0.72 \\
Total & 8684.89 & 24 & 2140.45 & - & - & 100 \\
\hline
\end{tabular}

Notes: SS, sum of squares; DF, degree of freedom; Var, mean square; $F, F$-value; and $p$, probability. 


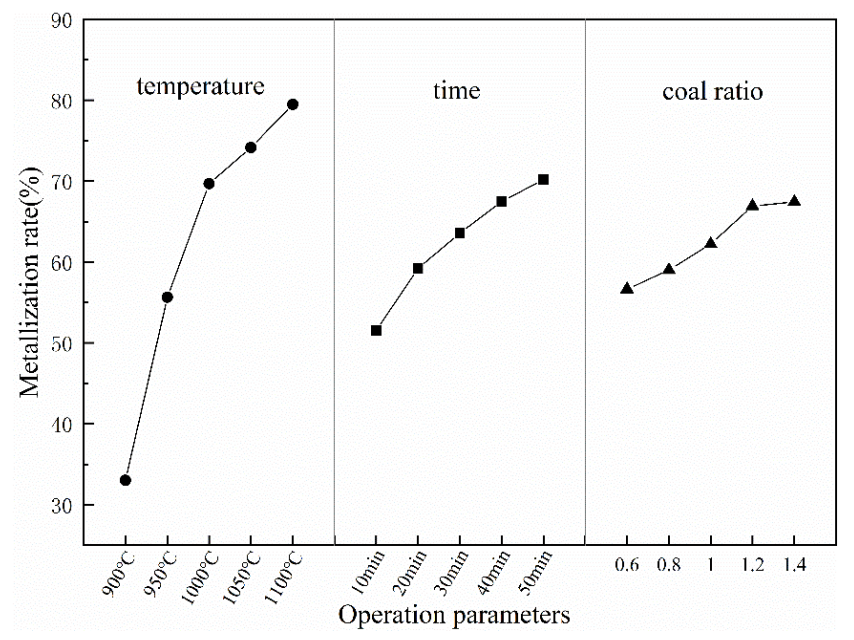

Figure 4. The values of the three selected parameters at the five designated levels for metallization rate of reduced samples.

3.2. Effect of Parameters on the Metallization Rate and Phase Change of the Pre-Reduction Process 3.2.1. Effect of Temperature

Figure 5 shows the effect of five consideration temperatures range from $900{ }^{\circ} \mathrm{C}$ to $1100{ }^{\circ} \mathrm{C}$ on the metallization of pellets and the phase change in the pre-reduction process with a holding time of $30 \mathrm{~min}$ and a coal ratio of 1.

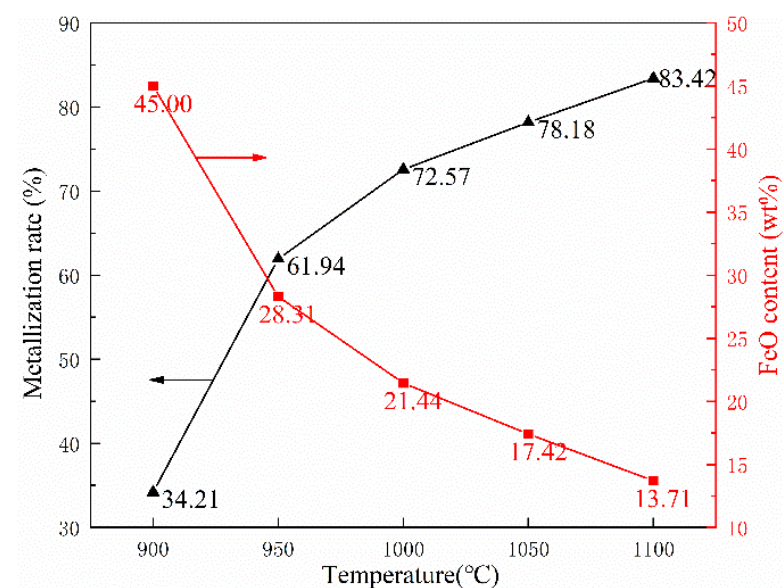

(a)

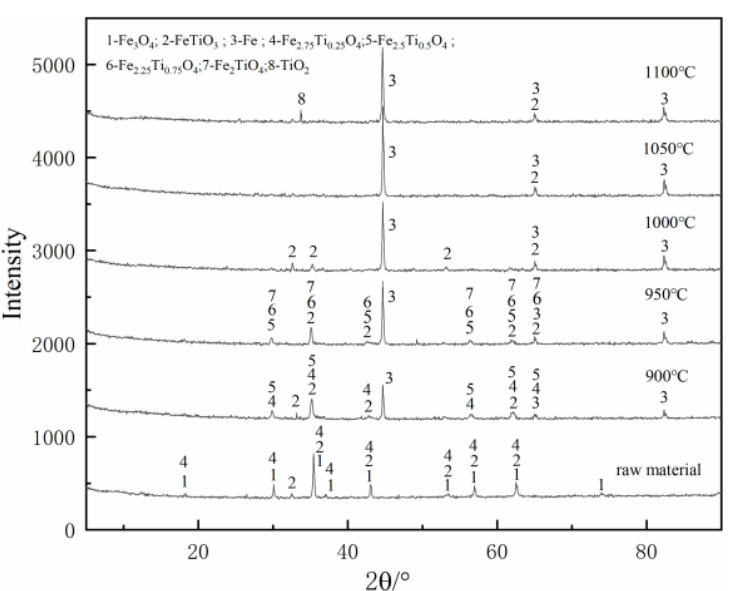

(b)

Figure 5. Effects of various reduction temperatures on composite's behaviors: (a) metallization ratio and FeO content and (b) phase change.

Figure 5a shows that the metallization rate was increased with the increase of temperature. The metallization was only $34.21 \%$ at $900{ }^{\circ} \mathrm{C}$, which was far away from the aim of $70 \%$. As the temperature rose to $950{ }^{\circ} \mathrm{C}$, the metallization rate increased by $27.73 \%$ to $61.94 \%$, which was almost twice the previous date at $900{ }^{\circ} \mathrm{C}$. As the temperature rose to $1000{ }^{\circ} \mathrm{C}$, the metallization rate increased by $10.63 \%$ and reached $72.57 \%$, which exceeds the target value of $70 \%$. As the temperature further increased, the increase of the metallization rate gradually decreased to about $5 \%$. When the temperature rose to $1050{ }^{\circ} \mathrm{C}$ and $1100{ }^{\circ} \mathrm{C}$, the metallization rates reached $78.18 \%$ and $83.42 \%$, respectively. We can also see from Figure $5 \mathrm{a}$ that as the reduction temperature increased, the FeO content of the pellets gradually decreased. The results demonstrate that increasing the temperature is beneficial 
to the reduction of FeO to metallic iron. Previous research [31,32] shows that the working temperature of the rotary kiln should be $100-150{ }^{\circ} \mathrm{C}$ lower than the soft melting point of pulverized coal to avoid the ring formation of the rotary kiln. Therefore, according to Table 3, the working temperature in the rotary kiln should be lower than $1030{ }^{\circ} \mathrm{C}$. Fully considering the metallization rate and the suppression of ring formation in the rotary kiln, the temperature of $1000{ }^{\circ} \mathrm{C}$ is the most reasonable parameter.

Compared with the raw material phase composition, it can be seen from Figure $5 \mathrm{~b}$ that magnetite $\left(\mathrm{Fe}_{3} \mathrm{O}_{4}\right)$ disappeared and metallic iron ( $\left.\mathrm{Fe}\right)$ appeared after reduction. Moreover, the peak value of Fe increased with the temperature increases, indicating that the increase in temperature can promote the reduction of iron oxides. The main phases of the sample at $900{ }^{\circ} \mathrm{C}$ include $\mathrm{Fe}, \mathrm{FeTiO}_{3}, \mathrm{Fe}_{2.75} \mathrm{Ti}_{0.25} \mathrm{O}_{4}$, and $\mathrm{Fe}_{2.5} \mathrm{Ti}_{0.5} \mathrm{O}_{4}$. As the temperature rose to $950{ }^{\circ} \mathrm{C}$, the $\mathrm{Fe}_{2.75} \mathrm{Ti}_{0.25} \mathrm{O}_{4}$ disappeared, the peaks of $\mathrm{Fe}_{2.25} \mathrm{Ti}_{0.25} \mathrm{O}_{4}$ and $\mathrm{Fe}_{2} \mathrm{TiO}_{4}$ were observed. When the temperature reached $1000{ }^{\circ} \mathrm{C}$, the $\mathrm{Fe}_{2.5} \mathrm{Ti}_{0.5} \mathrm{O}_{4}, \mathrm{Fe}_{2.25} \mathrm{Ti}_{0.25} \mathrm{O}_{4}$, and $\mathrm{Fe}_{2} \mathrm{TiO}_{4}$ disappeared. Finally, the traces of $\mathrm{TiO}_{2}$ were detected in the XRD pattern of the sample at $1100^{\circ} \mathrm{C}$.

\subsubsection{Effect of Coal Ratio}

The effect of coal ratio on the pre-reduction of pellets was studied at the reduction temperature of $1000^{\circ} \mathrm{C}$ and the holding time of $30 \mathrm{~min}$. According to the results illustrated in Figure $6 \mathrm{a}$, the metallization rate and $\mathrm{FeO}$ content curve could be divided into two stages. When the coal ratio increased from 0.6 to 1 , the metallization rate increased sharply from $59.08 \%$ to $72.57 \%$, and the FeO content curve decreased sharply from $32.37 \%$ to $21.44 \%$. When the coal ratio increased from 1 to 1.4, however, the metallization rate was increased slightly by $2 \%$ and the $\mathrm{FeO}$ content curve decreased marginally. Considering the economic and energy consumption, it is more appropriate to recommend 1 as the optimal coal ratio for the novel process.

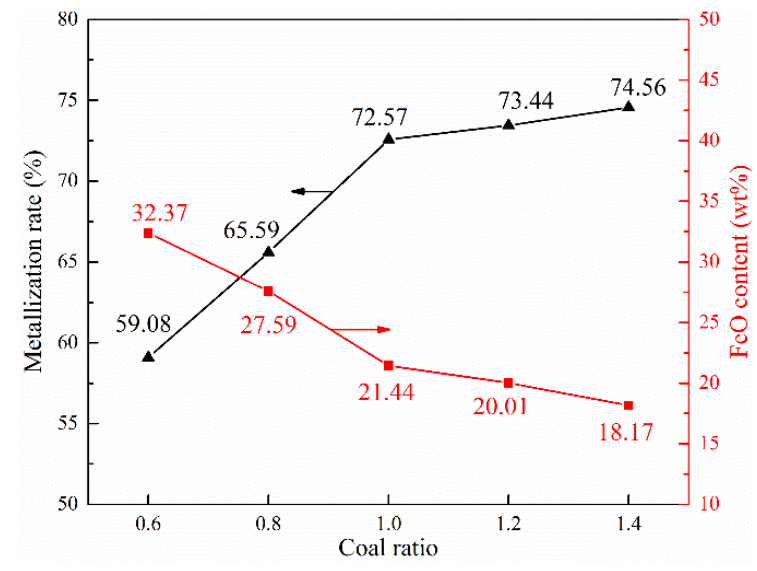

(a)

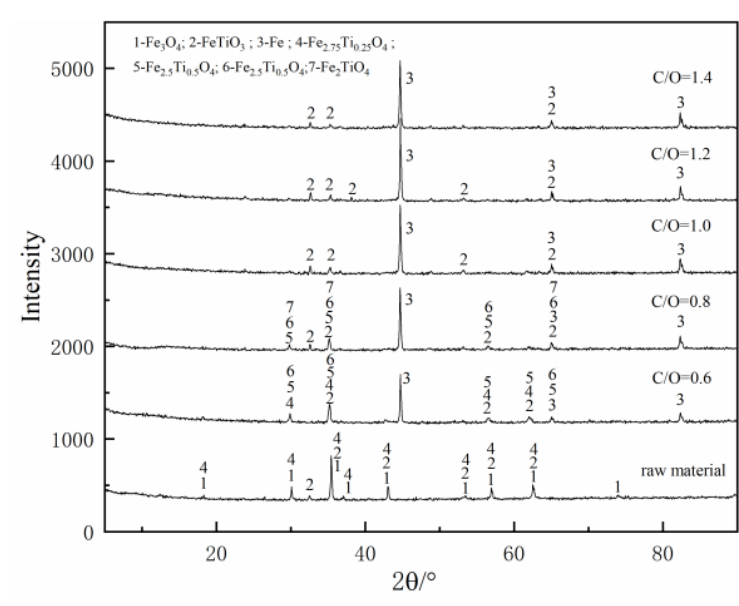

(b)

Figure 6. Effects of coal ratio on composite's behaviors: (a) metallization ratio and FeO content and (b) phase change.

Figure $6 \mathrm{~b}$ shows the XRD patterns of the reduced pellets with different coal ratios. It can be seen that the reduction reaction of iron oxides was increased with the increase of carbon content. At the low carbon contents (coal ratio were 0.6 and 0.8 ), $\mathrm{Fe}_{2.75} \mathrm{Ti}_{0.25} \mathrm{O}_{4}$, $\mathrm{Fe}_{2.5} \mathrm{Ti}_{0.5} \mathrm{O}_{4}, \mathrm{Fe}_{2.25} \mathrm{Ti}_{0.25} \mathrm{O}_{4}$, and $\mathrm{Fe}_{2} \mathrm{TiO}_{4}$ still existed in the reduced pellets, indicating that the reducing agent required for the reduction of those iron oxides was seriously insufficient. When the coal ratio increased to $1, \mathrm{Fe}_{2.75} \mathrm{Ti}_{0.25} \mathrm{O}_{4}, \mathrm{Fe}_{2.5} \mathrm{Ti}_{0.5} \mathrm{O}_{4}, \mathrm{Fe}_{2.25} \mathrm{Ti}_{0.25} \mathrm{O}_{4}$, and $\mathrm{Fe}_{2} \mathrm{TiO}_{4}$ phases were disappeared while only $\mathrm{FeTiO}_{3}$ and $\mathrm{Fe}$ peaks could be observed. The phase compositions were not changed while coal ratio up to 1.2 and 1.4. That is to say, under this condition, increasing the reducing agent could not promote the further reduction of the 
remaining Ti-bearing iron oxide $\left(\mathrm{FeTiO}_{3}\right)$, so there is no need to continue to increase the reducing agent.

\subsubsection{Effect of Holding Time}

Figure 7 shows the effect of different holding time on the reduction process, with the reduction temperature of $1000{ }^{\circ} \mathrm{C}$ and coal ratio of 1 .

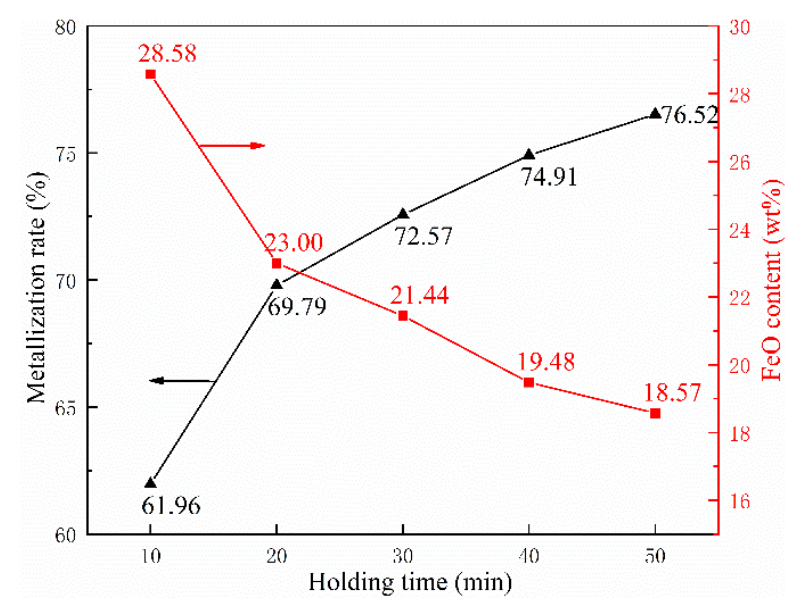

(a)

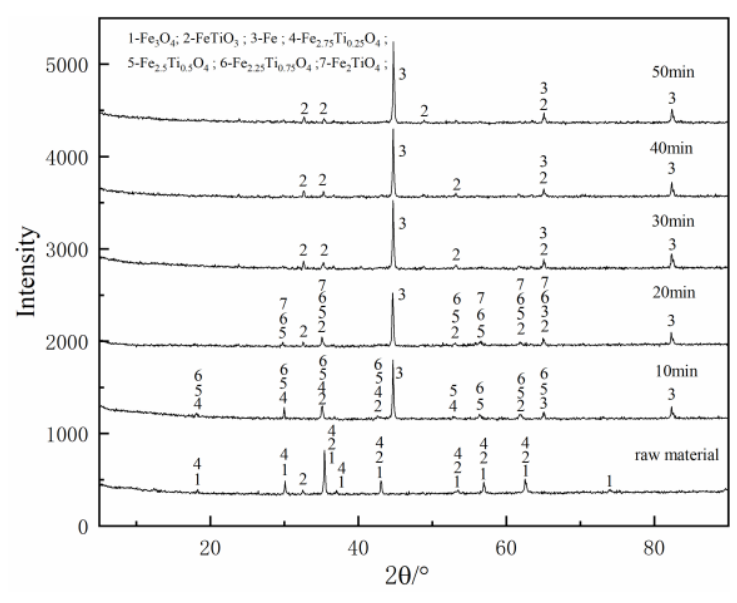

(b)

Figure 7. Effects of reduction holding time on composite's behaviors: (a) metallization ratio and FeO content and (b) phase change.

As presented in Figure 7a, the metallization rates were $61.96 \%$ and $69.8 \%$ at $10 \mathrm{~min}$ and $20 \mathrm{~min}$, respectively. When the holding time exceeds $30 \mathrm{~min}$, the metallization rate reaches $72.57 \%, 74.91 \%$, and $76.52 \%$ at the holding time $30 \mathrm{~min}, 40 \mathrm{~min}$, and $50 \mathrm{~min}$, respectively, and those metallization rates have already exceeded the target value of $70 \%$. Besides, as the reduction progresses, the content of $\mathrm{FeO}$ in the pellets becomes lower and lower. Those results demonstrate that extending holding time can promote the reduction of the pellets. However, as holding time increases, the increment of the metallization rate gradually decreases, and especially after $20 \mathrm{~min}$, each additional $10 \mathrm{~min}$ holding time increases the metallization rate by only about $2 \%$, much lower than $7.84 \%$ (the increase from 10 to $20 \mathrm{~min}$ ). Therefore, $30 \mathrm{~min}$ is the shortest time to reach the requirements.

The effect of holding time on the main phase transformation during the reduction was investigated by $\mathrm{XRD}$, as shown in Figure $7 \mathrm{~b}$. As the holding time reached $10 \mathrm{~min}, \mathrm{Fe}_{3} \mathrm{O}_{4}$ was disappeared and $\mathrm{Fe}_{2.75} \mathrm{Ti}_{0.25} \mathrm{O}_{4}$ was partly reduced to $\mathrm{Fe}_{2.5} \mathrm{Ti}_{0.5} \mathrm{O}_{4}$ and $\mathrm{Fe}_{2.25} \mathrm{Ti}_{0.25} \mathrm{O}_{4}$. Accompany with the holding time increased, the remaining $\mathrm{Fe}_{2.75} \mathrm{Ti}_{0.25} \mathrm{O}_{4}$ was gradually disappeared, and traces of $\mathrm{Fe}_{2} \mathrm{TiO}_{4}$ were detected in the XRD pattern. When the holding time reached to $30 \mathrm{~min}, \mathrm{Fe}_{2.5} \mathrm{Ti}_{0.5} \mathrm{O}_{4}, \mathrm{Fe}_{2.25} \mathrm{Ti}_{0.25} \mathrm{O}_{4}$, and $\mathrm{Fe}_{2} \mathrm{TiO}_{4}$ almost disappeared, and only left $\mathrm{FeTiO}_{3}$ and $\mathrm{Fe}$. Subsequently, the phase composition of the samples remained unchanged and the Fe peak did not change significantly, which indicates that increasing the holding time after 30 min only has a little effect on the metallization rate.

\subsection{Microstructural Characterization and Energy Spectrum Analysis}

The microstructures of the reduced pellets in different reduction temperature are shown in Figure 8. The black area in the figures indicates the pores inside the pellet (it is caused by the use of synthetic resin filling during sample preparation). As the temperature increases, the pores inside the samples gradually increased from Figure $8 \mathrm{a}, \mathrm{c}$ to Figure 8e. It is observed that Figure 8e has more pores than others. Besides, it can be seen from the comparison of Figure $8 \mathrm{~b}, \mathrm{~d}, \mathrm{f}$, that as the temperature rises, the metallic iron gradually gathers together to form agglomerates, and the particles gradually become bigger and rounded. The $\mathrm{Fe}_{3-\mathrm{x}} \mathrm{Ti}_{\mathrm{x}} \mathrm{O}_{4}$ phase sandwiched between the $\mathrm{Fe}$ phase and the slag phase 
gradually disappeared. The $\mathrm{FeTiO}_{3}$ phase is surrounded and in close contact with the metal iron phase, making it more difficult to be reduced.
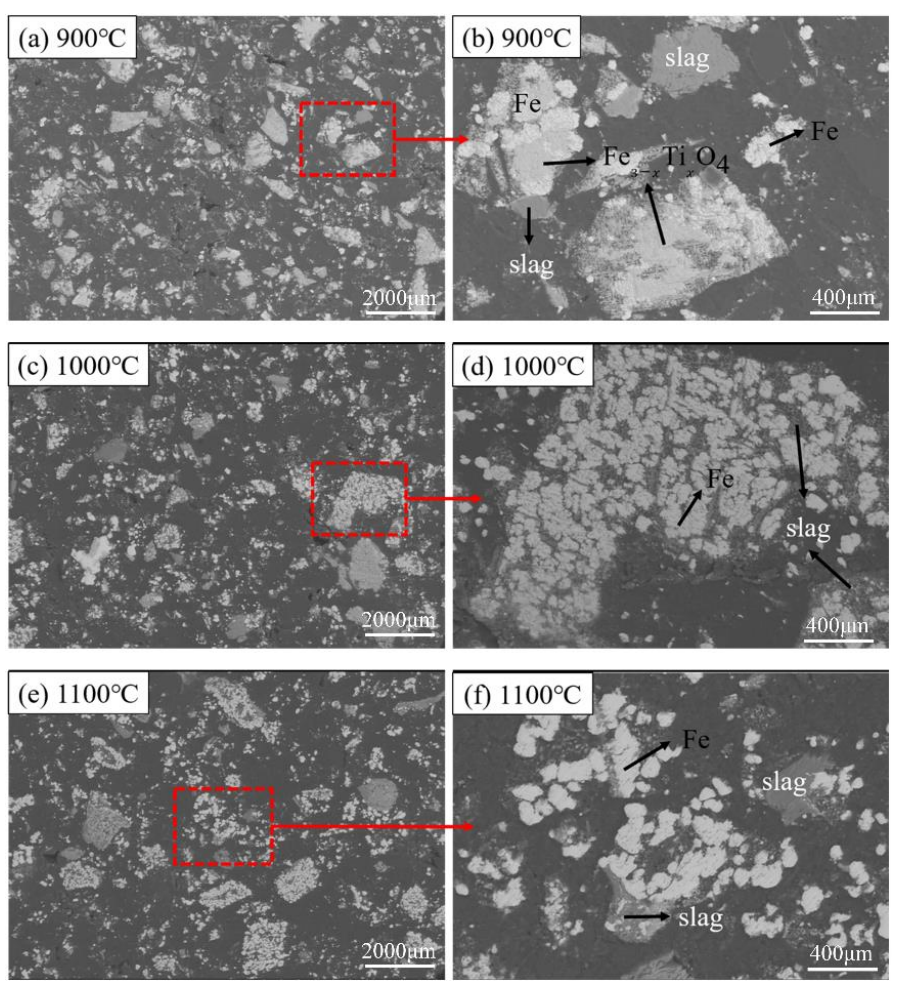

Figure 8. Microstructural characterization of samples on different reduction temperatures; (a,b) $900{ }^{\circ} \mathrm{C}$; (c,d) $1000{ }^{\circ} \mathrm{C}$; and (e,f) $1100{ }^{\circ} \mathrm{C}$.

As shown in Figure 9, the main elements of the reduced sample include $\mathrm{Fe}, \mathrm{Ti}, \mathrm{Ca}$, $\mathrm{Mg}, \mathrm{Al}, \mathrm{O}, \mathrm{Si}$, and $\mathrm{C}$. It can be seen from that the iron phase is mainly separated from slag, but tightly combined with titanium. Combined with the previous XRD analysis, it can be known that the titanium element mainly exists in the form of ilmenite. The ilmenite is widely distributed near the newly produced metal iron and is surrounded by the slag phase on the periphery, making the iron in ilmenite difficult to be reduced by the residual carbon distributed in the outermost part.
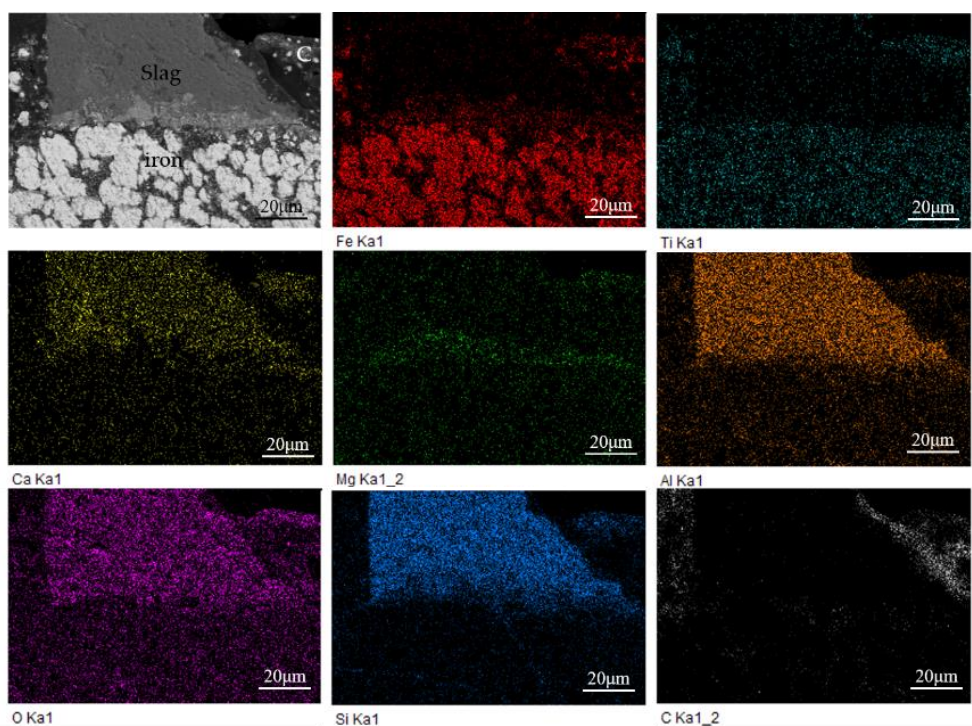

Figure 9. EDS elemental mapping of the reduced sample at $1000{ }^{\circ} \mathrm{C}$. 


\subsection{Off-gas Analysis of the Pre-Reduction Process}

Figure 10 shows the effect of temperature on the $\mathrm{CO}$ and $\mathrm{CO}_{2}$ contents in the off-gas. As we can see, the volume fractions of $\mathrm{CO}$ and $\mathrm{CO}_{2}$ both increase with the increase in temperature, but the increase of $\mathrm{CO}$ is more obvious. When the reduction temperature reaches $950^{\circ} \mathrm{C}$, the $\mathrm{CO}$ and $\mathrm{CO}_{2}$ contents curve begin to decline after reaching a peak during the insulation stage. As the temperature rises, this decline tends to advance significantly. Besides, it can be seen from Figure 10 that when the temperature reaches $1000{ }^{\circ} \mathrm{C}$, the volume fraction of $\mathrm{CO}$ and $\mathrm{CO}_{2}$ reaches about $20 \%$ and $5 \%$, respectively, and as the temperature continues to rise, the peak value changes are not obvious. This may be due to the high reactivity of lignite. The carbothermic reduction process of VTM generally could be divided into two parts. In the initial of the heating stage, the iron oxides are directly reduced by $\mathrm{C}$, at this time, the pellets release very little gas. As the reaction progresses, $\mathrm{CO}$ becomes the main reducing agent, which called indirect reduction. In the carbothermic reduction process, the Boudouard reaction is the most important. Due to the strong reactivity of lignite, when the temperature reaches about $100{ }^{\circ} \mathrm{C}$, the Boudouard Reaction has reacted thoroughly. Therefore, increasing the temperature can significantly accelerate the reduction of iron oxides, so that the CO content in the off-gas reaches a maximum value faster. Since the heating process is relatively slow, during the heating process, the most easily reducible magnetite in the VTM is rapidly reduced, leaving the hard-to-reduce titanomagnetite and ilmenite, so the off-gas drops rapidly. It should be emphasized that the $\mathrm{CO}$ and $\mathrm{CO}_{2}$ in the off-gas mainly come from the reduction of iron oxide and titanium oxide in the VTM. Therefore, the content of $\mathrm{CO}$ and $\mathrm{CO}_{2}$ in the off-gas can reflect the degree of mineral reduction from the side.

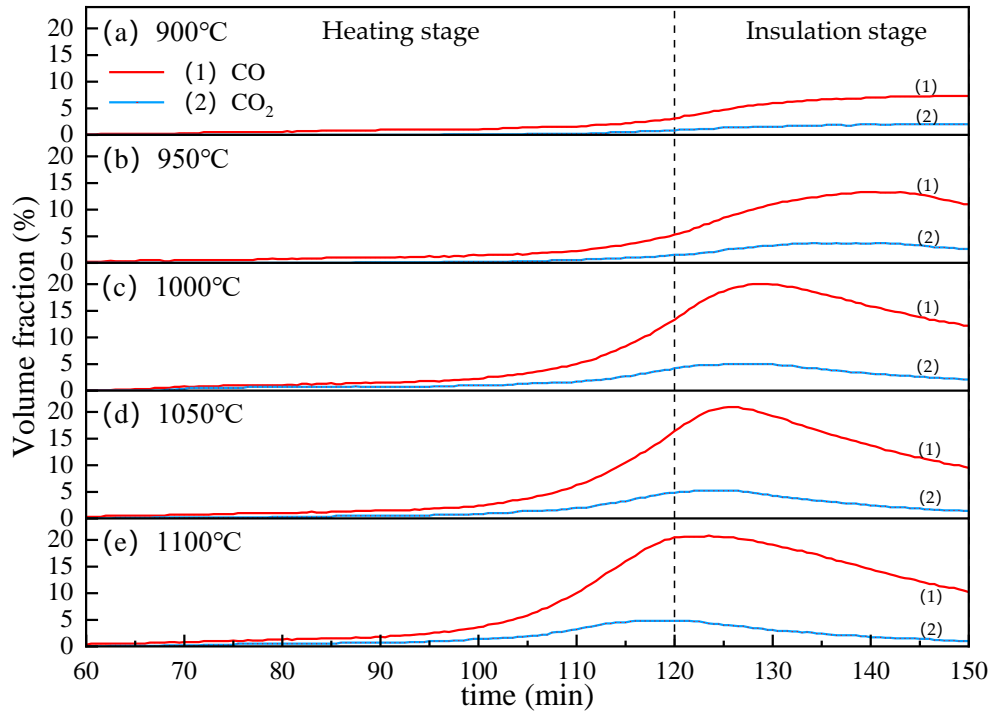

Figure 10. The effect of temperature on the $\mathrm{CO}$ and $\mathrm{CO}_{2}$ contents in the off-gas.

From Figure 11, we can see the effect of coal ratio on $\mathrm{CO}$ and $\mathrm{CO}_{2}$ contents in the off-gas. As the internal carbon content increases from 0.6 to 1 , the peak of $\mathrm{CO}$ volume fraction increases from about $15 \%$ to about $20 \%$. Continuing to increase the internal carbon content, the peaks of $\mathrm{CO}$ and $\mathrm{CO}_{2}$ did not increase and even dropped slightly at $\mathrm{C} / \mathrm{O}=1.2$. This may be because the increase in internal carbon resulted in a decrease in VTM content, which reduced the total content of oxygen that could be taken away by carbon in the reduction reaction. 


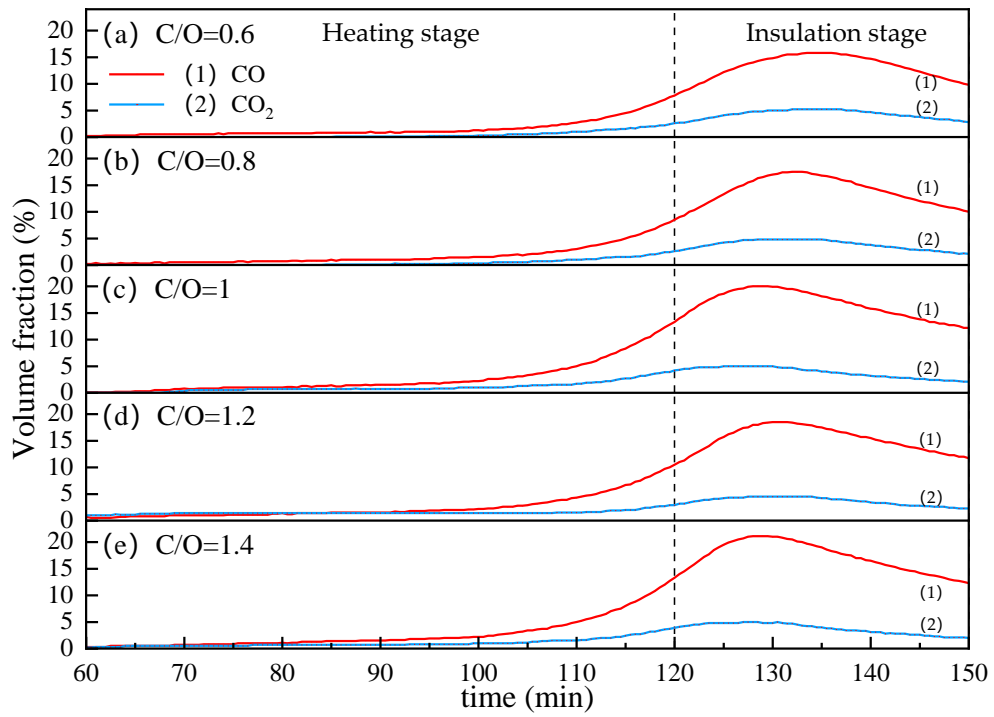

Figure 11. The influence of coal ratio on the $\mathrm{CO}$ and $\mathrm{CO}_{2}$ contents in the off-gas.

Figure 12 shows the influence of time on the $\mathrm{CO}$ and $\mathrm{CO}_{2}$ contents in the off-gas in the insulation stage with the reduction temple $1000{ }^{\circ} \mathrm{C}$ and coal ratio equals 1 . It can be found that the changing trend of the $\mathrm{CO}$ and $\mathrm{CO}_{2}$ curves is the same. When the temperature is kept for about $10 \mathrm{~min}$, the curve reaches a maximum value and then begins to decrease.

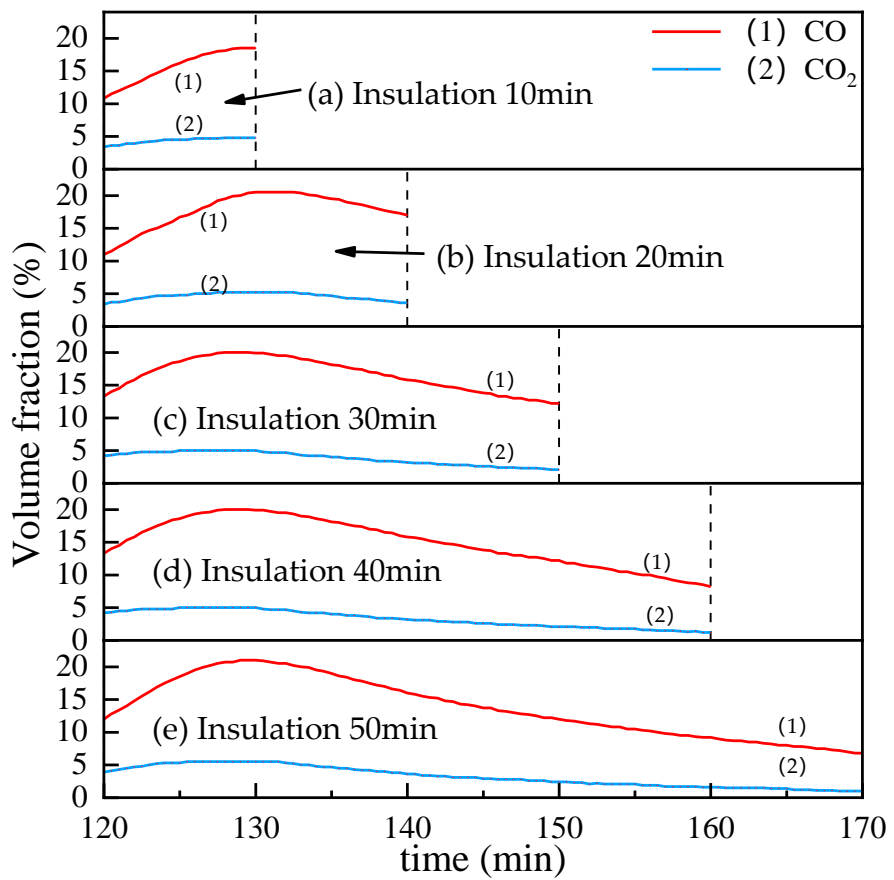

Figure 12. The influence of insulation time on the $\mathrm{CO}$ and $\mathrm{CO}_{2}$ contents in the off-gas.

Considering that CO plays a major role in the carbothermal reduction of VTM, the most critical reactions are as follows:

$$
\begin{gathered}
\mathrm{FeO}+\mathrm{CO}(\mathrm{g})=\mathrm{Fe}+\mathrm{CO}_{2}(\mathrm{~g}) \\
\mathrm{Fe}_{2} \mathrm{TiO}_{4}+\mathrm{CO}(\mathrm{g})=\mathrm{FeTiO}_{3}+\mathrm{Fe}+\mathrm{CO}_{2}(\mathrm{~g}) \\
\mathrm{FeTiO}_{3}+\mathrm{CO}(\mathrm{g})=\mathrm{TiO}_{2}+\mathrm{Fe}+\mathrm{CO}_{2}(\mathrm{~g})
\end{gathered}
$$


According to the thermodynamic data provided in the literature [33], the equilibrium $\mathrm{CO}_{2} / \mathrm{CO}$ values required for the free $\mathrm{FeO}, \mathrm{Fe}_{2} \mathrm{TiO}_{4}$, and $\mathrm{FeTiO}_{3}$ phases during the reduction of VTM by CO were calculated, as shown in Table 7. When the actual value of $\mathrm{CO}_{2} / \mathrm{CO}$ is greater than the corresponding required theoretical equilibrium value, the substance may not be reduced. Therefore, as can be seen from Table $7, \mathrm{FeO}$ is easily reduced, and it has the lowest requirements for reducing gas. $\mathrm{Fe}_{2} \mathrm{TiO}_{4}$ has a higher requirement for reducing gas, while $\mathrm{FeTiO}_{3}$ needs a huge increase in reducing gas. Moreover, the reduction potential of $\mathrm{CO}-\mathrm{CO}_{2}$ gas mixture increases with increasing temperature when reducing $\mathrm{FeTiO}_{3}$, and decreases with increasing temperature when reducing $\mathrm{FeO}$ and $\mathrm{Fe}_{2} \mathrm{TiO}_{4}$. Therefore, we can also roughly judge the progress of the VTM reduction process by observing the actual $\mathrm{CO}_{2} / \mathrm{CO}$ value. This is very important for process judgments in ironmaking production links that cannot be directly sampled.

Table 7. $\mathrm{CO}_{2} / \mathrm{CO}$ value required for different phases in $900-1100{ }^{\circ} \mathrm{C}$.

\begin{tabular}{cccccc}
\hline \multirow{2}{*}{ Reduced Phase } & \multicolumn{5}{c}{$\mathbf{C O}_{\mathbf{2}} / \mathbf{C O}$} \\
\cline { 2 - 6 } & $\mathbf{9 0 0}{ }^{\circ} \mathbf{C}$ & $\mathbf{9 5 0}^{\circ} \mathbf{C}$ & $\mathbf{1 0 0 0}{ }^{\circ} \mathbf{C}$ & $\mathbf{1 0 5 0}^{\circ} \mathbf{C}$ & $\mathbf{1 1 0 0}^{\circ} \mathbf{C}$ \\
\hline $\mathrm{Free} \mathrm{FeO}_{\mathrm{Fe}_{2} \mathrm{TiO}_{4}}$ & 0.562 & 0.518 & 0.480 & 0.447 & 0.419 \\
$\mathrm{FeTiO}_{3}$ & 0.270 & 0.249 & 0.232 & 0.216 & 0.203 \\
\hline
\end{tabular}

Figure 13 shows the reality $\mathrm{CO}_{2} / \mathrm{CO}$ value with different temperature in the off-gas of this study. It can be seen that as the reduction reaction progresses, the value of $\mathrm{CO}_{2} / \mathrm{CO}$ increases rapidly in the heating stage and then decreases. The exception is when the reduction temperature is $900{ }^{\circ} \mathrm{C}$, the curve still shows an upward trend in the insulation stage. This may be because the low temperature is not conducive to the reduction of iron oxides, and the $\mathrm{CO}_{2}$ generated by the reduction reaction quickly reacts with $\mathrm{C}$ to generate $\mathrm{CO}$. At the reduction endpoint $(150 \mathrm{~min})$, the reality $\mathrm{CO}_{2} / \mathrm{CO}$ value of $1100^{\circ} \mathrm{C}$ reached 0.098 , which is very close to the theoretical value of 0.097 , indicating that under the condition of $1100{ }^{\circ} \mathrm{C}, \mathrm{FeTiO}_{3}$ may be reduced. This is consistent with the $\mathrm{XRD}$ analysis results above. The $\mathrm{CO}_{2} / \mathrm{CO}$ values of $1050{ }^{\circ} \mathrm{C}, 1000{ }^{\circ} \mathrm{C}$ and $950{ }^{\circ} \mathrm{C}$ reached $0.147,0.172$, and 0.236 at the end of reduction, respectively. The values are both less than the theoretical value required for the corresponding $\mathrm{Fe}_{2} \mathrm{TiO}_{4}$ reduction, from which it is demonstrated that $\mathrm{FeO}$ has been completely reduced in those conditions. The $\mathrm{CO}_{2} / \mathrm{CO}$ values of $900{ }^{\circ} \mathrm{C}$ at the point of $150 \mathrm{~min}$ is 0.274 , which is bigger than the theoretical value of $\mathrm{Fe}_{2} \mathrm{TiO}_{4}$, meanwhile, its value still has an upward trend, indicating that $\mathrm{FeO}$ has not been reduced completely.

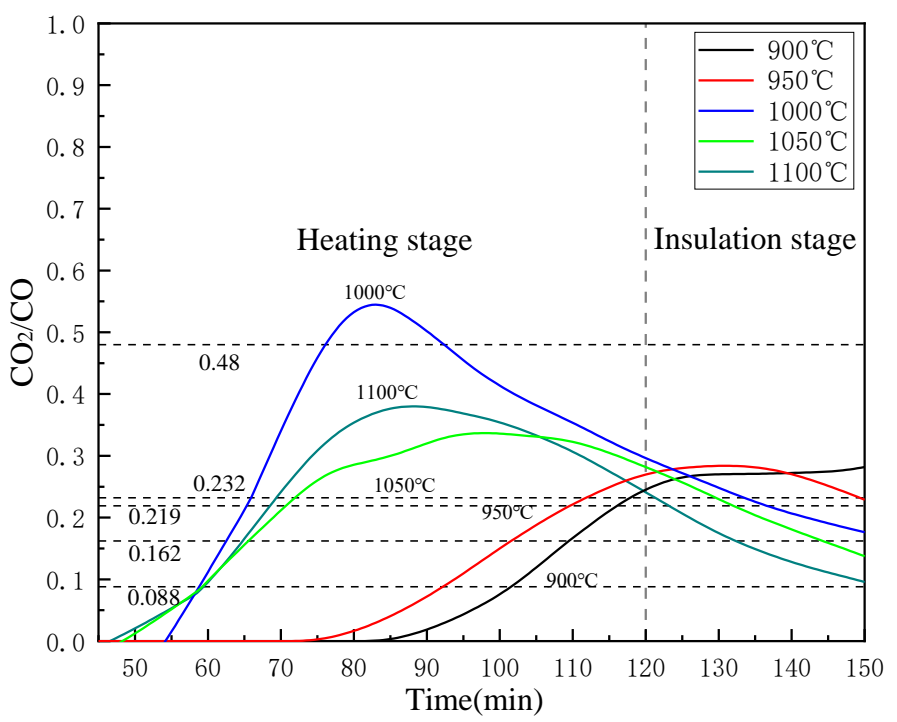

Figure 13. Effects of temperatures on $\mathrm{CO}_{2} / \mathrm{CO}$ in the off-gas. 
Reducing the value of $\mathrm{CO}_{2} / \mathrm{CO}$ is beneficial for the reduction of iron oxides, but as the value of $\mathrm{CO}_{2} / \mathrm{CO}$ decreases, a large amount of $\mathrm{CO}$ does not participate in the actual reaction, which will greatly reduce the utilization rate of $\mathrm{CO}$. That is undesirable from the perspective of energy utilization. Therefore, according to the process requirements, selecting the appropriate temperature and reduction time is necessary for saving energy. Therefore, the reduction temperature of $1000{ }^{\circ} \mathrm{C}$ is a suitable choice for this process.

Similarly, we analyzed the $\mathrm{CO}_{2} / \mathrm{CO}$ value with different coal ratios and reduction time conditions in the reduction process, mainly for the insulation stage, as shown in Figure 14 (Since the $\mathrm{CO}_{2} / \mathrm{CO}$ curves of different holding times are similar, we selected the $\mathrm{CO}_{2} / \mathrm{CO}$ values at the endpoints of different holding times and drew this curve). From Figure 14a, the curves gradually decrease with the increase of reaction time, and the curve with the higher the $\mathrm{C} / \mathrm{O}$ value, the lower the $\mathrm{CO}_{2} / \mathrm{CO}$ value. Therefore, increasing the internal carbon content is beneficial for the reduction of iron oxides. However, when $\mathrm{C} / \mathrm{O}=1.2$, its $\mathrm{CO}_{2} / \mathrm{CO}$ curve is above that of $\mathrm{C} / \mathrm{O}=1$ and the reason is not clear yet, needing further study. Figure $14 \mathrm{~b}$ shows that under the condition of the reduction temperature of $1000{ }^{\circ} \mathrm{C}$ and $\mathrm{C} / \mathrm{O}=1$, the $\mathrm{CO}_{2} / \mathrm{CO}$ curve decreases as approximately linear with the increase of time in insulation stage. Under the reduction temperature of $1000{ }^{\circ} \mathrm{C}$, the reduction condition of free $\mathrm{FeO}, \mathrm{Fe}_{2} \mathrm{TiO}_{4}$, and $\mathrm{FeTiO}_{3}$ are $\mathrm{CO}_{2} / \mathrm{CO}<0.480,<0.232$, and $<0.088$, respectively. It can be seen from Figure 14 that too low $\mathrm{C} / \mathrm{O}$ or too short reduction time is not conducive to the reduction of $\mathrm{Fe}_{2} \mathrm{TiO}_{4}$ in $\mathrm{VTM}$, and the reduction of $\mathrm{FeTiO}_{3}$ has too high requirements for the reduction gas, which is not economical for the pre-reduction process of rotary kiln, especially when using the top gas of the oxygen smelting furnace as the heat source for rotary kiln.

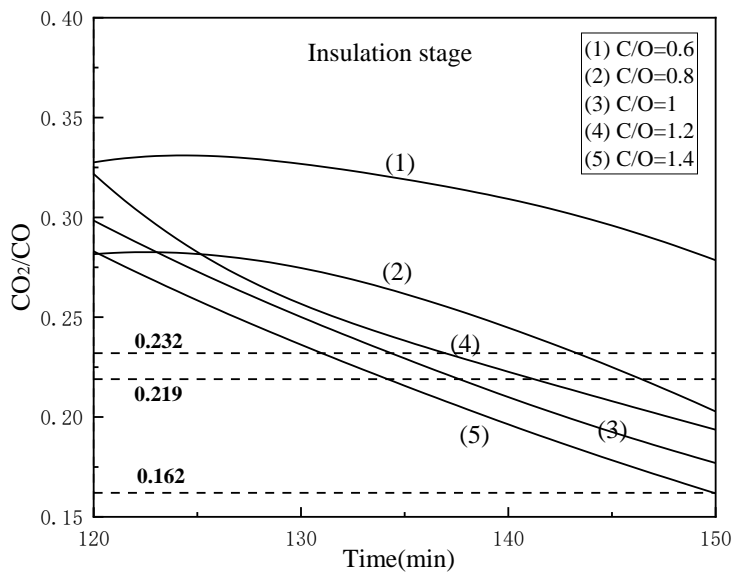

(a)

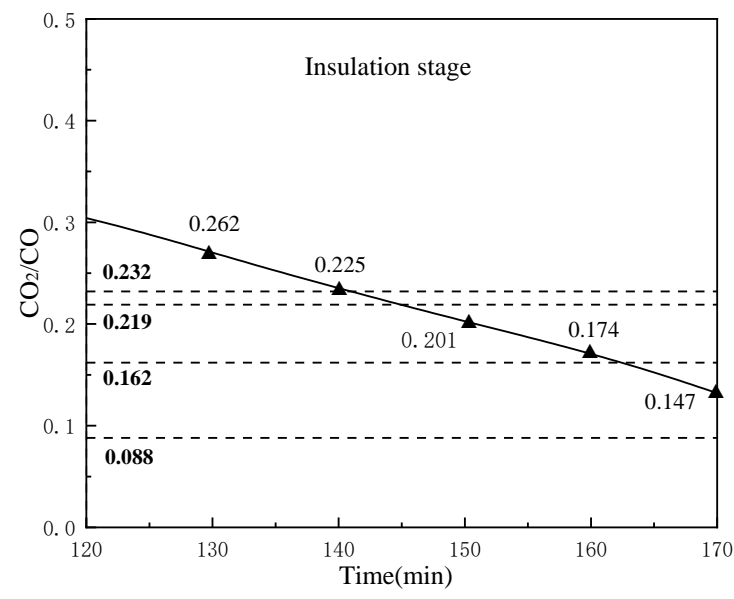

(b)

Figure 14. Changes of $\mathrm{CO}_{2} / \mathrm{CO}$ value under different conditions: (a) $100{ }^{\circ} \mathrm{C}, 30 \mathrm{~min}$ and different coal ratios and (b) $1000{ }^{\circ} \mathrm{C}, \mathrm{C} / \mathrm{O}=1$ and different reduction holding time.

According to the composition of the top gas of the oxygen smelting furnace calculated by Gao [15], the $\mathrm{CO}_{2} / \mathrm{CO}$ value range is approximately from 0.162 to 0.219 . Which means when the $\mathrm{CO}_{2} / \mathrm{CO}$ value of the gas released by the composite pellets is lower than 0.162 , the products will definitely be oxidized by the top gas. Therefore, it is very important to select an appropriate metallization rate according to the process conditions. Through the above analysis, we can see too high reduction temperature and too long reduction time may cause secondary oxidation of the products, furthermore increasing temperature and prolonging reduction time would consume more energy. Besides, increasing the amount of carbon will bring in more impurities and increase coal consumption. Thence in this rotary kiln process, when the reduction temperature is $1000^{\circ} \mathrm{C}$, the constant temperature reduction time is $30 \mathrm{~min}$ and $\mathrm{C} / \mathrm{O}=1$, the product's metallization rate is $72.57 \%$, and the $\mathrm{CO}_{2} / \mathrm{CO}$ value is 0.172 at the pre-reduction endpoint, which was the optimal parameters. 


\section{Conclusions}

This study introduces a novel iron-making process using rotary kiln as the prereduction equipment. Compared with the traditional BF process, the coking and sintering process is eliminated in the novel process and it has the characteristics of lower environmental pollution and more suitable smelting technology for special minerals. Through the laboratory research, we use vanadium-titanium magnetite as the raw material, and the proper metallization rate and its corresponding parameters were obtained. Variance analysis shows that parameters of reduction temperature, reduction holding time, and coal ratio have a remarkable influence on the metallization rate, occupying $81.25 \%, 12.6 \%$, and $5.43 \%$ of the total contribution, respectively. Among them, the temperature is the most important factor to determine the metallization rate. Under the condition of holding temperature of $1000{ }^{\circ} \mathrm{C}$, holding time of $30 \mathrm{~min}$, and coal ratio of 1 , the pre-reduced pellets with a metallization rate of $72.57 \%$ and the $\mathrm{CO}_{2} / \mathrm{CO}$ value is 0.172 at the pre-reduction endpoint were obtained, which meet the process requirements and was the most suitable and most energy-saving parameters. Continuing to increase the temperature, holding time, and coal ratio can raise the metallization rate of the pellets, but only with a little improvement and accompanied by greater energy consumption.

Author Contributions: Conceptualization, B.W. and X.D.; methodology, B.W.; resources, X.D.; data curation, X.Z.; writing-original draft, B.W.; writing-review and editing, G.C.; visualization, X.Z. and T.J.; supervision, T.J.; project administration, X.D. All authors have read and agreed to the published version of the manuscript.

Funding: This research was funded by the National Key Research Development Program of China, grant number 2017YFB0603801 and 2017YFB0603800.

Data Availability Statement: All data generated or analyzed during this study are included in this article.

Conflicts of Interest: The authors declare no conflict of interest.

\section{References}

1. Hasanbeigi, A.; Arens, M.; Price, L. Alternative emerging ironmaking technologies for energy-efficiency and carbon dioxide emissions reduction: A technical review. Renew. Sust. Energ. Rev. 2014, 33, 645-658. [CrossRef]

2. Bellevrat, E.; Menanteau, P. Introducing carbon constraint in the steel sector: ULCOS scenarios and economic modeling. Revue Métallurgie 2009, 106, 318-324. [CrossRef]

3. You, Y.; Li, Y.Y.; Luo, Z.G.; Li, H.F.; Zou, Z.S.; Yang, R.Y. Investigating the effect of particle shape on the charging process in melter gasifiers in COREX. Powder Technol. 2019, 351, 305-313. [CrossRef]

4. Wang, H.T.; Chu, M.S.; Zhao, W.; Liu, Z.G.; Tang, J. Influence of Iron ore addition on metallurgical reaction behavior of iron coke hot briquette. Metall. Mater. Trans. B 2019, 50, 324-336. [CrossRef]

5. Sahu, R.K.; Halder, C.; Sen, P.K. Optimization of top gas recycle blast furnace emissions with implications of downstream energy. Steel Res. Int. 2016, 87, 1190-1202. [CrossRef]

6. An, R.Y.; Yu, B.Y.; Li, R.; Wei, Y.M. Potential of energy savings and CO2 emission reduction in China's iron and steel industry. Appl. Energy 2018, 226, 862-880. [CrossRef]

7. Dong, K.; Wang, X.L. CO2 utilization in the ironmaking and steelmaking process. Metals 2019, 9, 273. [CrossRef]

8. Yao, S.; Wu, S.L.; Wang, S.Y.; Tang, Z.Y.; Yang, J.H.; Zhou, H.; Song, B.; Kou, M.Y. A mathematical model of COREX process with top gas recycling. Steel Res. Int. 2020. [CrossRef]

9. Wu, S.L.; Xu, J.; Yang, S.D.; Zhou, Q.; Zhang, L.H. Basic characteristics of the shaft furnace of COREX (R) smelting reduction process based on iron oxides reduction simulation. ISIJ Int. 2010, 50, 1032-1039. [CrossRef]

10. Li, W.G. Operation status quo and technical problems of COREX-3000. Baosteel Tech. 2008, 6, 11-18. (In Chinese)

11. Pokhvisnev, Y.V.; Valavin, V.S.; Makeev, S.A.; Zaitsev, A.K. Romelt process production indices with partial replacement of coal by natural gas. Metallurgist 2019, 63, 141-148. [CrossRef]

12. Jianjun, G.; Lukuo, H.; Jun, Z.; Yuanhong, Q.; Dingliu, Y. Experiment study of vanadium titano-magnetite by full oxygen bath smelting process. ISVT 2018, 39, 8-13. (In Chinese)

13. Jianjun, G.; Xinyu, W.; Yuanhong, Q.; Feng, W. Technical analysis on ironmaking process of rotary kiln pre-reduction and smelting by coal and oxygen. J. Iron Steel Res. 2018, 30, 91-96. (In Chinese)

14. Van Staden, Y.; Beukes, J.P.; van Zyl, P.G.; Ringdalen, E.; Tangstad, M.; Kleynhans, E.L.J.; Bunt, J.R. Damring formation during rotary kiln chromite pre-reduction: Effects of pulverized carbonaceous fuel selection and partial pellet melting. Met. Mater. Trans. B 2018, 49, 3488-3503. [CrossRef] 
15. Jianjun, G. Basic Research for Vanadium Titano-magnetite Extracted by Rotary Kiln Pre-reduction and Full Oxygen Bath Smelting Process. Ph.D. Thesis, Central Iron and Steel Research Institute, Beijing, China, March 2018. (In Chinese).

16. She, X.F.; Sun, H.Y.; Dong, X.J.; Xue, Q.G.; Wang, J.S. Reduction mechanism of titanomagnetite concentrate by carbon monoxide. J. Min. Met. Sect. B Met. 2013, 49, 263-270. [CrossRef]

17. Zhao, W.; Chu, M.; Liu, Z.; Wang, H.; Tang, J.; Ying, Z. High-temperature interactions between vanadium-titanium magnetite carbon composite hot briquettes and pellets under simulated blast furnace conditions. Met. Mater. Trans. B 2019, 50, 1878-1895. [CrossRef]

18. Cheng, G.J.; Xue, X.X.; Liu, J.X.; Jiang, T.; Duan, P.N. Reduction kinetics and mechanism of pellets prepared from high chromium vanadium-titanium magnetite concentrate. Trans. Inst. Min. Met. Process. Sect. C 2017, 126, 125-132. [CrossRef]

19. Liu, J.X.; Cheng, G.J.; Liu, Z.G.; Chu, M.S.; Xue, X.X. Reduction process of pellet containing high chromic vanadium-titanium magnetite in cohesive zone. Steel Res. Int. 2015, 86, 808-816. [CrossRef]

20. Li, W.; Fu, G.Q.; Chu, M.S.; Zhu, M.Y. An effective and cleaner process to recovery iron, titanium, vanadium, and chromium from Hongge vanadium titanomagnetite with hydrogen-rich gases. Ironmak. Steelmak. 2020, 1-7. [CrossRef]

21. Xing, X.D.; Du, Y.L.; Zheng, J.L.; Chen, Y.F.; Ren, S.; Ju, J.T. Experimental study on strengthening carbothermic reduction of vanadium-titanium-magnetite by adding CaF2. Minerals 2020, 10, 219. [CrossRef]

22. Ma, H.B.; Jiao, K.X.; Zhang, J.L. The influence of basicity and $\mathrm{TiO} 2$ on the crystallization behavior of high Ti-bearing slags. CrystEngComm 2020, 22, 361-370. [CrossRef]

23. Xing, X.D.; Wang, S.; Pang, Z.G.; Zhang, Q.L. Effect of B2O3 on the carbothermal reduction of vanadium titanium magnetite. Met. Res. Technol. 2019, 116, 9.

24. Cheng, G.J.; Gao, Z.X.; Lv, M.Y.; Yang, H.; Xue, X.X. Coal-based reduction and magnetic separation behavior of low-grade vanadium-titanium magnetite pellets. Minerals 2017, 7, 86. [CrossRef]

25. Zhou, M.; Jiang, T.; Ding, X.Y.; Ma, S.H.; Wei, G.; Xue, X.X. Thermodynamic study of direct reduction of high-chromium vanadium-titanium magnetite (HCVTM) based on phase equilibrium calculation model. J. Therm. Anal. Calorim. 2019, 136, 885-892. [CrossRef]

26. Yang, S.T.; Tang, W.D.; Zhou, M.; Jiang, T.; Xue, X.X.; Zhang, W.J. Effects of dolomite on mineral compositions and metallurgical properties of chromium-bearing vanadium-titanium magnetite sinter. Minerals 2017, 7, 15. [CrossRef]

27. Zhang, J.L.; Xing, X.D.; Cao, M.M.; Jiao, K.X.; Wang, C.L.; Ren, S. Reduction kinetics of vanadium titano-magnetite carbon composite pellets adding catalysts under high temperature. J. Iron Steel Res. Int. 2013, 20, 1-7. [CrossRef]

28. Hongbing, W.; Yanzhong, J.; Delan, L.; Haiqiao, W. Experimental research on direct reduction for carbon-containing pellets of vanadium-titanium magnetite. Res. Iron Steel 2017, 45, 23-25.

29. Liu, S.S.; Guo, Y.F.; Qiu, G.Z.; Jiang, T.; Chen, F. Solid-state reduction kinetics and mechanism of pre-oxidized vanadium-titanium magnetite concentrate. Trans. Nonferrous Met. Soc. China 2014, 24, 3372-3377. [CrossRef]

30. Zhong, Q.; Yang, Y.B.; Jiang, T.; Li, Q.; Xu, B. Effect of coal ash on ring behavior of iron-ore pellet powder in kiln. Powder Technol. 2018, 323, 195-202. [CrossRef]

31. Jiang, T.; He, G.Q.; Gan, M.; Li, G.H.; Fan, X.H.; Yuan, L.S. Forming mechanism of rings in rotary-kiln for oxidized pellet. J. Iron Steel Res. Int. 2009, 16, 292-297.

32. Liang, Z.K.; Yi, L.Y.; Huang, Z.C.; Lu, B.; Jiang, X.; Cai, W.; Tian, B.Z.; Jin, Y.Y. Insight of iron ore-coal composite reduction in a pilot scale rotary kiln: A post-mortem study. Powder Technol. 2019, 356, 691-701. [CrossRef]

33. Chen, J.W.; Jiao, Y.; Wang, X.D. Thermodynamic studies on gas-based reduction of vanadium titano-magnetite pellets. Int. J. Min. Met. Mater. 2019, 26, 822-830. [CrossRef] 